November - 2009

\title{
Peer-To-Peer Recognition of Learning in Open Education
}

\author{
Jan Philipp Schmidt \\ United Nations University MERIT \\ Christine Geith \\ Michigan State University \\ Stian Håklev \\ University of Toronto \\ Joel Thierstein \\ Rice University
}

\begin{abstract}
Recognition in education is the acknowledgment of learning achievements. Accreditation is certification of such recognition by an institution, an organization, a government, a community, etc. There are a number of assessment methods by which learning can be evaluated (exam, practicum, etc.) for the purpose of recognition and accreditation, and there are a number of different purposes for the accreditation itself (i.e., job, social recognition, membership in a group, etc). As our world moves from an industrial to a knowledge society, new skills are needed. Social web technologies offer opportunities for learning, which build these skills and allow new ways to assess them.

This paper makes the case for a peer-based method of assessment and recognition as a feasible option for accreditation purposes. The peer-based method would leverage online communities and tools, for example digital portfolios, digital trails, and aggregations of individual opinions and ratings into a reliable assessment of quality. Recognition by peers can have a similar function as formal accreditation, and pathways to turn peer recognition into formal credits are outlined. The authors conclude by presenting an open education assessment and accreditation scenario, which draws upon the attributes of open source software communities: trust, relevance, scalability, and transparency.
\end{abstract}

Keywords: Open education; assessment; accreditation; participatory learning 


\section{Background}

Open education is the combination of open licensing and web-based social media. It brings some fundamental challenges to the way we think about higher education and the institutional arrangements in which it is organized (Katz, 2008; Liyoshi \& Kumar, 2008). ${ }^{1}$

Enabled by widespread adoption of the Internet, large, self-organized, open innovation communities, such as open source software projects or Wikipedia (http://wikipedia.org/), have emerged. These projects are open to participation by anyone (within limits), regardless of background, location, or credentials. They challenge the notion that formally credentialed "experts" are the only producers of knowledge or the sole sources of innovation. Collaboration takes place in complex meritocratic arrangements, and social capital is accumulated in the form of recognition and reputation within the community.

Similar open approaches have successfully been implemented in education, creating new models for research publication, textbook development and publication, and teaching and learning. Open access journals are starting to show higher citation and survival rates than closed proprietary journals (Morrison, 2007; Crawford, 2006). Member institutions of the OpenCourseWare Consortium in over 30 countries have published more than 8,000 courses for free use, adaptation, and distribution (http://www.ocwconsortium.org/). ${ }^{2}$ Connexions, an open educational resources repository, has nearly 15,000 modules, or learning objects, woven together in over 750 collections, which are used by over one million people per month in over 200 countries (http://cnx.org/). On WikiEducator (http://wikieducator.org/), teachers from many countries have come together to author over 16,000 course modules, and in South Africa, the Free Science Textbook Project has harnessed the power of volunteers to create high-quality free textbooks that are appropriate to the local curriculum (http://www.fhsst.org/). In addition to the publication of open educational resources, educators at Utah State University (http://opencontent.org/wiki), Otago Polytechnic (http://wikieducator.org/Facilitating_online_communities), and the University of Manitoba (http://ltc.umanitoba.ca/wiki/Connectivism) are successfully experimenting with opening access to their teaching beyond registered students and letting participants share in the design of course structure and content. And new projects like the Peer 2 Peer University (http://www.p2pu.org) are suggesting that web-based social software can enable peer learning outside of existing institutions.

As demonstrated above, the Internet, social networking applications, and evolving social norms enabled by technology have begun to change many aspects of the traditional education landscape. However, there are currently few mechanisms to recognize informal learning in a way that leads to individual accreditation. Some students who are enrolled in degree programmes have been able to negotiate credits for "open courses" on a case-by-case basis; and at least one institution has applied "course challenge" policies to users of its open courseware materials and awarded credit to learners able to meet faculty-determined performance measures ${ }^{\underline{3}}$. Much work has been done in the field of prior learning assessment and recognition, which theoretically allows informal online learners to transition into formal education (Konrad, 2001). These existing opportunities are 
attempts to tweak the current accreditation system, rather than fundamentally rethink the concept of accreditation within an open peer-production paradigm.

Scholars have considered the implications of open approaches for teaching and learning practices, for the development of course materials, and for the sustainability models for higher education institutions (Benkler 2008; Geith, 2008a, 2008c; Geith \& Vignare, 2008; Katz, 2008; Liyoshi \& Kumnar, 2008; Schmidt, 2008), but a comprehensive investigation of how an open model can provide new forms of formal accreditation, as well as allow pathways to formal credit, is missing. In this paper we discuss accreditation in the context of open peer-to-peer communities. We introduce the roles and functions that accreditation has historically performed for students and institutions, for example as a measure of human capital or an indication of group membership. We then describe forces that influence the role of accreditation, the need for new skills as we move from a service-based society to an information society, and the opportunities created by peer-to-peer learning in the social web. Finally, we describe existing pathways from reputation to formal credits, summarize the key characteristics of an open education accreditation model, and provide a learning scenario that highlights these features.

\section{Definitions: Recognition, Accreditation, Academic Credit, and Assessment}

The key concepts we use to develop our argument are recognition, accreditation, and assessment. In conversations outside of academia these are often not differentiated clearly, but even in the academic literature, they can have different connotations. For this reason, we briefly highlight how the terms are used in this paper.

Recognition is the acknowledgment of achievements and conveys approval by the person, group, or organization doing the recognizing. Recognition can be implicit (for example, use of the original work by another author/citation) or explicit (for example, in the form of gradually increasing responsibilities within a community, by attribution of contributions, or via a badge or other tangible form that communicates recognition). Recognition can be provided by members of a community itself, or by outsiders. Open source software communities are a good example of implicit and explicit recognition of achievements. Experienced and/or qualified contributors' opinions carry more weight in discussions, and contributions are explicitly acknowledged as signed software code that is accepted into the published version of a program.

Accreditation is formal certification by a third party or intermediary (institution, community of practice, guild, etc.). Accreditation implies that the receiver meets the standards of the accreditor. For learning systems, accreditation applies to individuals as well as to institutions and to programs, but with respect to students, the commonly used term is "certified" rather than "accredited." For individual learners accreditation provides formal credentials such as academic credit hours, a license, diploma, certificate, or degree. For institutions, such as colleges and universities, it provides endorsements, branding, and access to markets and resources through accreditation by governments, professional associations, and other accreditation bodies (Wellman $\&$ Thomas, 2003). 
Assessment is the process of determining the characteristics of something or someone. In the case of learners, this means determining their individual knowledge, behaviors, and/or skills, and it provides a necessary basis for recognition or accreditation (Voorhees, 2001). There are a number of assessment methods by which learning can be determined, including observation, exam, and practicum, as well as impression and gut feeling, etc. Methods of assessment lead to formal judgement or classification. In education, assessment aims to be replicable and objective, and we distinguish between assessment of learning, for learning (summative), and as learning (formative) (Earl \& Katz, 2006).

\section{The Role of Accreditation}

Accreditation of individuals has important economic, social, and political consequences. Not simply "units of knowledge," credentials represent trust and socio-political status. They are also part of the formal rules of organizations that allow access to certain positions through cultural assumptions of competence and loyalty (Brown, 2001). As open education evolves, it is important for the open education movement to reflect upon the role of accreditation, how it can be provided to individuals who need it, and how its valuable features can be preserved even when institutional arrangements are less clearly defined.

As societies become more complex, post-secondary institutions are called upon to train for traditional and emerging occupations, to sort out qualified job candidates, and to perform the role of examiner. "A university degree is a prerequisite for an increasing number of occupations in most societies. Indeed, academic certification is necessary for most positions of power, authority, and prestige in modern societies, which places immense power in the hands of universities" (Altbach, Berdahl, \& Gumport, 1999, p. 22). Not only individuals but also institutions are accredited by the governments that charter them and by outside organizations, such as professional accreditation bodies, and this is critical to institutional operations and brand. Accredited institutions receive quality recognition among informed consumers, their students are eligible for state licensure (where required), and their students are eligible for government funding, such as federal financial aid, scholarships, loans, and work/study funds in the U.S.

There have been several critical perspectives on the function of educational accreditation in society. For example, Bills (1988) lists four main views: human capital, credentialism, screening, and cultural capital. Let us consider these four with a view to how they conceptualize education and accreditation and to how they could be applied to concepts of open education. Firstly, Becker (1964) introduced the concept of human capital and the idea that just as one could invest in infrastructure or better machines to increase productivity, investing in training and education of human resources would make workers more productive and would generate economic benefits to both the individual workers and to society as a whole. This idea, which rapidly gained currency, was an important factor in the dramatic expansion of higher education in North America and Europe during the last fifty years. Human capital theory fits into the functionalist framework, where the expansion of higher education is seen as responding to a real need for better trained people in the industry (Dornbusch, Glasgow, \& Lin, 1996). Credentials signal skills and expertise 
beneficial to the economy and reduce the transaction costs of having to review each worker's competencies individually.

The three other theories could be said to fit in under the conflict theory of education, where schools are arenas for power struggles between different groups in society. Credentialism, as propounded by Berg (1971) and Dore (1976), is the persistent social trend towards everincreasing educational requirements for jobs, which is not connected to any rise in job complexity. This is often called credential inflation. Credentialism theorists agree with human capital theorists that credentials are beneficial to those who receive them and lead to higher salaries and better jobs, but according to Boylan (1993), the link between education and productivity is much weaker than the link between education and rewards; thus, diplomas entitle you to society's spoils, but you or the credentials are not necessarily responsible for producing them. In Boylan's view, expanding education should have little positive effect on overall wealth and may devalue credentials and increase inequality among groups. According to screening theory, people with high educational achievements really are more productive workers but not because of the "value added" from education. Rather, formal education is seen as an (expensive) method for sorting out those workers who have innate capabilities for working better or who are more receptive to on-the-job training (Tyler, 1982). Finally, cultural capital theorists like Collins (1979) and Bordieu (1973) believed that formal schooling's main function is to provide the "mainly non-cognitive 'cultural capital' that helps dominant groups maintain their status" (Bills, 1988, p. 440). Thus, the future leaders are taught to dress, to socialize, to speak, to take initiative, and to work independently; whereas, students in schools serving working class neighborhoods are more likely to be taught docility, punctuality, and obedience to authority.

\section{The Need for New Skills and Abilities}

Assessment and accreditation practices are always a reflection of their times - and so are the skills that are in demand at a certain point in history (Carnevale \& Desrochers, 2001; Kohl \& LaPidus, 2000). In the networked world that Yochai Benkler describes in The Wealth of Networks (2007), the tools to produce and process information - computers and networks - have become abundant. Richard Murnane and Frank Levy (2004) argue that new skills - 21st century skills are required to make use of these abundant technologies. Such skills are more procedural than factual and allow us to analyze complex data and to communicate effectively. George Siemens's (2005) connectivism theory of learning goes beyond traditional theories of learning (such as behaviorism, cognitivism, and constructivism) to include technology as a core element. He argues that factual knowledge becomes less important than mastering the use of networked connections between ever-changing specialized information. He suggests that "[o]ur ability to learn what we need for tomorrow is more important than what we know today." To those that resist such a fundamental rethinking of what skills are needed by future graduates, the authors of the PISA study (OECD, 2006) reply that the alternative to developing 21st century skills comes at the risk of educating a work force that is ill-prepared for the knowledge economy:

... if students learn merely to memorise and reproduce scientific knowledge and skills, they risk being prepared mainly for jobs 
that are disappearing from labour markets in many countries. In order to participate fully in today's global economy, students need to be able to solve problems for which there are no clear rule-based solutions and also to communicate complex scientific ideas clearly and persuasively. (p. 33, OECD, 2006)

Assessing these new competencies requires detailed understanding of the communities and scenarios in which they can be applied. Exams are not useful tools to evaluate a learner's ability to identify, organise, synthesize, and apply information from various sources on the Web. To be fair, there are various efforts to improve assessment in light of the changing demands of a knowledge economy, or to simply improve the current levels of efficiency and accuracy. The PISA study (OECD, 2006) makes useful suggestions regarding science assessment, and Earl and Katz (2006) describe how better assessment practices can improve classroom teaching. However, despite improvements in methodology, assessment practices have a tendency to focus on easily quantifiable measurements rather than contextualized behaviors, dispositions, and attitudes.

For our open education accreditation model, we are interested in retaining the goal in accreditation of accurately reflecting learning and skills to enable individuals and firms to negotiate employment arrangements efficiently. However, we also acknowledge that the skills needed in the 21 st century are radically different from those tested and accredited in the past. Open education communities have certain unique characteristics that are ideally suited to the development and recognition of such new abilities in its individual members.

\section{Open Education}

One effect of the open education movement has been that some parts of the education package typically provided by institutions that drew value from scarcity have become abundant. For example, educational content for many subjects is now freely and openly available online. This has led some open education proponents to speak of the "disaggregation of education" (see blog posts Wiley 2008a, Wiley 2008b, and Norman 2008) and to speculate how other core services of the university might evolve as independent elements in an open education ecosystem. Such ecosystems are typically described as a combination of three areas: content, learning support, and accreditation (integrated with assessment). We will take a closer look at learning, assessment, and accreditation in open education (content holds no particular relevance in the context of accreditation).

\section{Peer-to-Peer Learning in Open Education}

Using an analogy from network technology, peer-to-peer learning, assessment, and accreditation are anchored in an understanding of learning as participatory, open, and community-based (van Gennip, Segers, Tillema, 2009). In the education literature, peers are often defined as members of a cohort or students with similar or complementary skills. We propose that peers can be of different ages and backgrounds, and we draw on the technical definition of peer-to-peer networking. The term peer-to-peer ( $\mathrm{P} 2 \mathrm{P})$ refers to a network of equals (peers) in which two or 
more individuals are able to spontaneously collaborate without necessarily needing central coordination (Schoder \& Fischbach, 2003). In contrast to client/server networks, P2P networks promise improved scalability, lower cost of ownership, self-organized and decentralized coordination of previously underused or limited resources, greater fault tolerance, and better support for building ad hoc networks. In addition, P2P networks provide opportunities for new user scenarios that could scarcely be implemented using customary approaches (Schoder, Fischbach, \& Schmitt, 2005).

Translating this understanding of computer networks to learning models leads us to participatory community-based learning groups, which stand in contrast to the instructor-led model that is akin to a client-server model. Atkins, Brown, and Hammond (2007) propose the development of an open participatory learning infrastructure (OPLI) to enable a global learning ecosystem, which includes a focus on peer-learning. Stephen Downes (2005) builds on the concept of a community of practice (Lave \& Wenger, 1991) as a group "characterized by 'a shared domain of interest' where 'members interact and learn together' and 'develop a shared repertoire of resources."'

Some of the technologies and opportunities that exist today are new, but the ideas and concepts have been around for much longer. Ivan Illich in his 1971 classic, Deschooling Society, envisages a future where obligatory schooling is abolished; rather, each person is given at birth a number of education tokens to be used at their leisure. There would be networks where people interested in the same book or movie could call a certain phone number then arrange to meet at a cafe for an intellectual discussion. Similarily, in today's peer-to-peer society, everyone would be able to teach and learn from each other in a distributed (peer-to-peer) fashion. People would begin contributing to the knowledge base at an early age, and "life-long learning" would be a reality.

\section{Assessment in Open Education}

As we have described above, the learning theories behind peer-to-peer learning are not new. The concepts behind collaborative learning, online communities, and distance education have been with us for many years. However, the social web has created new opportunities to collaboratively learn and to track such learning.

As users of the social web, more of what we do is collaborative, and sharing knowledge becomes a standard practice rather than the exception. Our identities, including educational identities, are increasingly digital and distributed across the Web. As a result, the boundaries and barriers between traditional education and informal learning are breaking down. Participating in online communities of practice can lead to significant learning, even though it does not happen within an education institution or program.

This new learning environment provides opportunities to leverage technology for assessment in various ways:

- Digital portfolios: Portfolios allow users to create their own learning stories, which could serve as the basis for recognition and accreditation. In such a portfolio the learner curates a selection of qualitative and quantitiative evidence and artifacts and testimonials to 
represent expertise, experience, and reputation (Carraccio \& Englander, 2004). Professional networking communities like LinkedIn (http://www.linkedin.com) are already providing many of the features that would be required for such a portfolio.

- Digital trails: The ability to evaluate the digital trails of our participation in communities. Beyond portfolios that are curated by the learner, more and more of our work is publicly accessible and can be considered for assessment. Blog posts we write, documents we create online, twitter messages (http://twitter.com) we send all contribute to an impression of who we are. These trails include our behaviour in electronic learning environments. Research on electronic learning is making progress with the evaluation of educational resources by tracking indicators of student's use and performance (Lovett, Meyer, \& Thille, 2008; Dickson, 2005).

- Aggregating individual opinions and ratings into a reliable assessment of quality: News portals like digg (http://digg.com) or reddit (http://reddit.com) make use of aggregated opinions of their users. The articles that receive the highest numbers of votes are published on the front page. Social bookmarking services like Delicious (http://www.delicious.com) use similar mechanisms to filter popular web resources. The premise is that a web page that has been bookmarked by thousands of users is likely to contain more relevant information than a page that only one person selected. The same principles could be applied to everything we produce in the process of learning. Others already leave opinions about our work and expertise: Readers comment on our blogs and pictures; they edit our wiki entries, or they disagree with arguments we make on mailing lists. We need to find ways to aggregate these opinions. Reputation models that calculate levels of trust for each person can further improve the accuracy of such systems (Marti \& Molina, 2006; Josan \& Boyd, 2007).

\section{Accreditation in Open Education}

Scholars have begun to speculate about the institutional and individual models for accreditation in open education (see, for example, Keats \& Schmidt, 2007; Downes, 2007; Geith, 2008b; Matkin, 2008; Wiley, 2008a). Keats and Schmidt (2007) argue that new institutions and organizations will start "competing with today's universities in any combination of higher education services, including research, teaching, and accreditation."

Jeff Young's recent article in the Chronicle of Higher Education (September 25, 2008) kicked off an animated conversation about the changes that have already taken place. Young asked "When Professors Print Their Own Diplomas, Who Needs Universities?" and used the example of David Wiley's "Open Edu 2008" course to make his point (http://opencontent.org/wiki/index.php?title=Intro_Open_Ed_Syllabus). Professor Wiley had offered to print certificates for anyone who participated and to provide evaluations for students at other institutions. 


\section{Existing pathways between peer-to-peer learning and formal education.}

Pathways that allow students to move between informal learning and formal accreditation already exist. Geith (2008b) describes the range of options that exist for open education communities, including competency-based testing, prior learning assessment and recognition, and the passing of standard exams that are accepted for credit. In addition, experience in David Wiley's Open Edu 2008 course shows that students were able to arrange for credit in their home institutions even though the course was taught and assessed by someone at a different university. The majority of students who ended up receiving credit for the course were in fact not registered at Utah State University, where Wiley taught at the time.

Open education can take advantage of existing pathways to individual accreditation in the form of academic credit and credentials. It also has an opportunity to blaze a new trail using the data inherent in online peer communities, and the concept of community reputation, to assess and recognize learning in new ways. These new methods could prove useful for not only linking to existing credit paths but also for creating new measures designed to recognize learning outcomes in open online communities. The idea of a completely open and community-based assessment and recognition model is intriguing.

\section{An open education assessment and accreditation scenario.}

To broaden Jeff Young's original question and ask "what if anyone could print their own diplomas?" it is useful to identify the key characteristics of a functioning accreditation system that is relevant in today's context and then consider how they could be realized in an open education environment. ${ }^{4}$ To do so, we draw on examples from open source software communities and then develop a brief open education accreditation scenario below.

- Trust: When accreditation needs to provide recognition beyond the community where it is expressed, its value is determined by the trust that is placed in the provider. There are different ways of expressing trust in open source projects, for example through their ability to attract and maintain participants or through the demonstrable quality of the project's output.

- Relevance: The assessment and accreditation mechanisms must be appropriate to evaluate and certify relevant learning and skills. Assessment must be an integral part of learning. In open source software, development and assessment are inseparable. The assessment of an individual's contribution is expressed by its acceptance into the actual software code.

- Scalability: The model must scale to the demands of the current education environment. A one-on-one system in which a trusted professor manually certifies a student does not scale well. A community-based reputation or voting system scales more easily, but outsiders might question its reliability. Open source software projects have demonstrated an ability to organically develop coordination, quality review, and feedback mechanisms that span communities of hundreds of participants. 
- Transparency: The possibility to examine all elements of the accreditation system increases trust and quality. Accreditation providers that show how they accredit learners with different assessment results reduce the potential for bias and for subjective accreditations. Errors can be identified and corrected easily. Open systems are by definition transparent and encourage inspection and improvements, leading to high standards of accountability.

The following scenario provides an example of what an open education assessment and accreditation could look like. It is not universally applicable to all disciplines, topics, and students, but it serves to highlight the potential for innovation. It is just one example of many possible ones.

A group of self-learners interested in behavioral economics agrees on a timeframe (6 weeks) and basic communication tools (email, aggregated blog posts, and a shared wiki workspace) to learn about the predictable irrationalities in human behavior. Each week the group members study the list of agreed readings and work through the tasks they have defined for themselves.

Their work in the group leaves a digital trail. They find useful resources and add them to a social bookmarking service with a short description and rating; when they read a blog post by another group member, they use a web browser plug-in to leave a short rating as well; when they review each other's assignments, they leave notes and ratings that are intended for both the author and themselves as reminders of especially good work (or of pitfalls to avoid). Others who are not part of the initial group can comment and leave additional feedback, suggest additional readings, or extend the discussions on their own blogs.

At the end of the course the group members each create their own personal portfolios in which they compile their best pieces of writing (or those that received positive feedback). They also leave testimonials for each other describing not only each other's mastery of the subject but also reflections on the experience of working together. In addition, a number of metrics are calculated automatically and included in the portfolio, such as the number of bookmarks that were stored, the number of ratings left, and the average rating received for their own work. There are also indicators of their level of engagement with the group and the particular roles they took on during the process, such as problem solving and peer review roles.

One of the learners applies for a job that requires a basic understanding of consumer behavior. She submits a link to her portfolio along with her CV. The interviewer is impressed by her portfolio and by the fact that it was completely self-motivated and offers her a job. As she works on projects in her new job, she links the final versions to her e-portfolio. A year later she decides to enter a master's program in strategic decision making and submits the e-portfolio to the university. The Recognition of Prior Learning department reviews the portfolio, contacts some of the people who left testimonials for 
references, and agrees to waive the required entry-level course. Another group member, who is based in the U.S., already has a number of college credits and is working towards a BSc degree. He contacts a private university that offers competency-based testing services, writes an exam, and is awarded college-level credits.

\section{Conclusion}

Accreditation plays an important role for individuals and society as a reflection of individual expertise and experience. As our world moves from an industrial to a knowledge society, new skills are needed. Social web technologies offer opportunities for learning, which build these skills and allow new ways to assess them. Peer-to-peer communities of learners can take advantage of pathways to formal academic credit; furthermore, new ways of open recognition are emerging.

These communities might provide new opportunities for non-traditional forms of learning, such as life-long learning and learning in areas that are not well served by existing institutions, as well as help to meet the increasing demand for education that cannot be provided by traditional learning venues.

This leads to exciting new opportunities for further research. For example, a better understanding of indicators for knowledge and skills in open education communities is needed. Such indicators would consider processes and describe types of communication and interaction as well as behaviors within a community of learners. In addition, we do not yet understand the motivations that might drive individuals to participate in community accredited learning opportunities, or the benefits they receive. 


\section{References}

A selection of online resources, including many of the following articles and blog posts, have been tagged as "opencredit" in the diigo and del.icio.us bookmarking services.

Atkins, D.E., Brown, J.S., \& Hammond, A.L. (2007). A review of the open educational resources (OER) movement: Achievements, challenges, and new opportunities (Report to the William and Flora Hewlett Foundation). Retrieved from http://www.oerderves.org/wp-content/uploads/2007/03/a-review-of-the-openeducational-resources-oer-movement_final.pdf.

Altbach, P.G., Berdahl, R. O., \& Gumport, P. J. (Eds.) (1999). American higher education in the twenty-first century: Social, political, and economic challenges. Baltimore, MD: The Johns Hopkins University Press.

Becker, G.S. (1964). Human capital. New York, NY: National Bureau of Economic Research.

Benkler, Y. (2007). The wealth of networks. New Haven, CT: Yale University Press.

Benkler, Y. (2008). The university in the networked economy and society: Challenges and opportunities. In R. N. Katz (Ed.), The tower and the cloud: Higher education in the age of cloud computing (pp. 51-61). Washington, DC: Educause.

Berg, I. (1971). Education and jobs: The great training robbery. New York, NY: Prager Publishers.

Bills, D.B. (1988). Credentials and capacities: Employers' perceptions of the acquisition of skills. The Sociological Quarterly, 29(3), 439-449.

Bordieu, P. (1973). Cultural reproduction and social reproduction. In R. Brown (Ed.), Knowledge, education, and cultural change (pp. 71-112). London: Tavistock.

Boylan, D. (1993). The effect of the number of diplomas on their value. Sociology of Education, 66(3), 206-221.

Brown, D.K. (2001). The social sources of educational credentialism: Status cultures, labor markets, and organizations. Sociology of Education, 74, Extra issue: Currents of Thought: Sociology of Education at the Dawn of the $21^{\text {st }}$ Century, 19-34.

Carnevale, A. P., \& Desrochers, D. M. (2001). Help wanted ...credentials required: Community colleges in the knowledge economy. Anapolis Junction, MD: Community College Press.

Carraccio, C., \& Englander, R. (2004). Evaluating competence using a portfolio: A literature 
review and web-based application to the ACGME competencies. Teaching and Learning in Medicine: An International Journal, 16(4), 381-387.

Collins, R. (1979). The credential Society: An historical sociology of education and stratification. New York, NY: Academic Press.

Crawford, W. (2006). Pioneer OA journals: The arc of enthusiasm, five years later. Cites \& Insights, 6(12), 1-6.

Dickson, P. (2005, October). Toward a deeper understanding of student performance in virtual high school courses. Paper presented at the meeting of the North American Council for Online Learning, Denver, Colorado.

Dore, R. P. (1976). The diploma disease: Education, qualification, and development. Berkeley, CA: University of California Press.

Dornbusch, S. M., Glasgow, K. L., \& Lin, I. (1996). The social structure of schooling. Annual Review of Psychology, 47, 401-429.

Downes, S. (2005). E-learning 2.0. eLearn Magazine. Retrieved from http://www.elearnmag.org/subpage.cfm?article=29-1\&section=articles

Downes, S. (2007, June 6). Open source assessment [Web log post]. Retrieved from http://halfanhour.blogspot.com/2007/06/open-source-assessment.html.

Earl, L., \& Katz, S. (2006). Rethinking classroom assessment with purpose in mind. Assessment for learning, assessment as learning, assessment of learning. Retrieved from Western and Northern Canadian Protocol for Collaboration in Education (WNCP) website: http://www.wncp.ca/media/40539/rethink.pdf.

Geith, C. (2008a). Teaching and learning unleashed with Web 2.0 and open educational resources. In R.N. Katz (Ed.), The tower and the cloud: Higher education in the age of cloud computing. Washington, DC: Educause. Retrieved from http://www.educause.edu/thetowerandthecloud.

Geith, C. (2008b). OCWC concept discussion paper: Linking credit and OpenCourseWare. Retrieved from http://docs.google.com/View?docid=df9f5w7f_3gwtcbwhf.

Geith, C. (2008c). Can OER really impact higher education and human development? Series of posts to the OSS and OER in Education Series in Terra Incognita blog archived at http://cnx.org/content/m19864/latest/.

Geith, C., \& Vignare K. (2008d). Access to education with online learning and open educational 
resources: Can they close the gap? Journal of Asynchronous Learning Networks, 12(1). Retrieved from http://www.sloan-c.org/publications/jaln/v12n1/pdf/v12n1_geith.pdf.

Hirst, T. (2008, September 20). Time to build trust with an “open achievements API"? [Web log post]. Retrieved from http://ouseful.wordpress.com/2008/09/20/time-to-build-trust-with-an-open-achievementsapi/.

Illich, I. (1971). Deschooling society. New York, NY: Harper \& Row.

Josang, A., Ismail, R., \& Boyd, C. (2007). A survey of trust and reputation systems for online service provision. Decision Support Systems, 43(2), 618-644.

Katz, R. N. (2008). The tower and the cloud: Higher education in the age of cloud computing. Washington, DC: Educause.

Keats, D.W., \& Schmidt J.P. (2007). The genesis and emergence of education 3.0 in higher education and its potential for Africa. First Monday, 12(3). Retrieved from http://firstmonday.org/issues/issue12_3/keats/index.html.

Kohl, K. J., \& LaPidus, J. B. (2000). Postbaccalaureate futures: New markets, resources, credentials. Series on Higher Education: American Council on Education. Phoenix: Oryx Press.

Konrad, J. (2001). Accreditation of prior learning in the United Kingdom (Working paper). Retrieved from http://www.leeds.ac.uk/educol/documents/00001831.htm.

Lave, J.C., \& Wenger, E. (1991). Situated learning: Legitimate peripheral participation. New York, NY: Cambridge University Press.

Liyoshi, T., \& Kumar, M.S. V. (2008). Opening up education: The collective advancement of education through open technology, open content, and open knowledge. Cambridge: MIT Press.

Lovett, M., Meyer, O., \& Thille, C. (2008). The Open Learning Initiative: Measuring the effectiveness of the OLI statistics course in accelerating student learning. Manuscript submitted for publication.

Marti, S., \& Molina, H. G. (2006). Taxonomy of trust: Categorizing P2P reputation systems. Computer Networks, 50(4), 472-484.

Matkin, G. W. (2008). Opening the gate on learning pathways: The next frontier in the open educational resource movement. Retrieved from http://unex.uci.edu/pdfs/dean/matkin_learningpathways.pdf. 
Morrison, H. (2007, July 6). Are open access journals ten times more likely to survive? [Web log post]. Retrieved from http://poeticeconomics.blogspot.com/2007/07/are-open-accessjournals-ten-times-more.html.

Murnane, R. J., \& Levy, F. (2004). The new division of labor: How computers are changing the way we work. Princeton, NJ: Princeton University Press.

Norman, D. (2008, September 29). On the three parts of open education [Web log post].

Retrieved from http://www.darcynorman.net/2008/09/29/on-the-three-parts-of-openeducation/.

OECD (2006). PISA 2006 science competencies for tomorrow's world (Vol. 1, Analysis). Paris: Organisation for Economic Cooperation and Development.

Schoder, D., \& Fischbach, K. (2003). Peer-to-peer prospects. Communications of the ACM, 46(2), 27-29.

Schoder, D., Fischbach, K., \& Schmidtt, C. (2005). Core concepts in peer-to-peer (P2P) networking. In R. Subramanian \& B. Goodman (Eds.), P2P computing: The evolution of a disruptive technology. Hershey, PA: Idea Group Inc.

Schmidt, J.P. (2008). Open courseware as an example for user-centric innovation in higher education - towards a new social role of the university. Proceedings of the 4th Barcelona Conference on Higher Education. Barcelona: Global University Network for Innovation.

Schmidt, J.P., \& Surman, M. (2007). Open sourcing education: Learning and wisdom from iSummit 2007. Retrieved from http://icommons.org/resources/open-sourcing-educationlearning-and-wisdom-from-isummit-2007.

Siemens, G. (2005). Connectivism: A learning theory for the digital age.

Retrieved from http://www.elearnspace.org/Articles/connectivism.htm.

Siemens, G. (2008). History of open content. Retrieved from University of Manitoba website: http://ltc.umanitoba.ca/connectivism/?p=156.

Tyler, W. (1982). Complexity and control: The organisational background of credentialism. British Journal of Sociology of Education, 3(2), 161-172.

van Gennip, N. A. E., Segers, M., \& Tillema, H. H. (2009). Peer assessment for learning from a social perspective: The influence of interpersonal and structural features. Learning and Instruction. 4(1), pp. 41-54.

Voorhees, R. A. (Ed.). (2001). Measuring what matters: Competency-based learning models in 
higher education. New Directions for Institutional Research, No. 110. New York: John Wiley \& Sons.

Wellman, J. V., \& Ehrlich, T. (2003). How the student credit hour shapes higher education. New directions in higher education, no. 122. San Francisco: Jossey-Bass.

Wiley, D. (2008a, September 29). More on the three parts of open education [Web log post]. Retrieved from http://opencontent.org/blog/archives/580.

Wiley, D. (2008b, September 30). On open accreditation [Web log post]. Retrieved from http://opencontent.org/blog/archives/585.

Wolanin, T. R. (2003). The student credit hour: An international exploration. In J. V. Wellman \& T. Ehrlich (Eds.), How the student credit hour shapes higher education: New directions in higher education, no. 122 (pp. 100-103). San Francisco: Jossey-Bass.

Young, J. (2008, October 3). When professors print their own diplomas, who needs universities? The Chronicle of Higher Education.

$1 \mathrm{We}$ use the term open to refer to participatory and collaborative practices, such as in open source software, rather than distance learning.

2Unpublished data from OpenCourseWare Consortium.

3.See example at Utah State University above.

4Some of these ideas were inspired by blog posts and the comments that readers left in response to the posts. See Young (2008), Wiley (2008a, 2008b), Siemens (2008) as starting points.

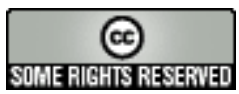

